\title{
Prevention of pressure sores by identifying patients at risk
}

\author{
KLAUS E ANDERSEN，OVE JENSEN，SVEN ANCHER KVORNING， ELSA BACH
}

\begin{abstract}
The risk of pressure sores developing in patients admitted with acute conditions was assessed by a simple risk score system based on age, reduced mobility, incontinence, pronounced emaciation, redness over bony prominences, unconsciousness, dehydration, and paralysis in a prospective clinical study. During seven months in 1977, 600 of 3571 patients were classified as at risk. Of these, 35 $(5.8 \%)$ developed sores compared with five $(0.2 \%)$ of those not at risk. The results of this study compared with those over the same period in 1976 show that close observation of at-risk patients and early detection of pressure sores prevents their development.
\end{abstract}

\section{Introduction}

Pressure sores present a problem for the health services despite medical progress, since improved treatment and knowledge allow even seriously ill patients to live longer.

In two surveys based on questionnaires the incidence of pressure sores was 3\% in Denmark ${ }^{1}$ and $8.8 \%$ in the United Kingdom. ${ }^{2}$ In a Danish study in 1976, 528 inpatients were examined in one day; of these, $11 \%(58)$ had pressure sores and a further $2 \cdot 8 \%(20)$ had pressure marks. ${ }^{3}$ The case records reported either sores or marks in only 51 of the 78 patients; in 47 patients preventive measures had been taken or treatment given. In groups of patients particularly at risk the incidences were higher. ${ }^{45}$

Pressure sores are a costly burden to the health services. ${ }^{\circ}$ Treatment under the National Health Service in Britain in 1973 cost about $£ 60$ million. ${ }^{2}$ The incidence can be reduced by improving routine care and using prophylactic equipment. ${ }^{2}$ Although such methods as turning regimens, water-beds, alternating-pressure air mattresses, ${ }^{8}{ }^{9}$ air-fluidised, and netsuspension beds, ${ }^{10}{ }^{11}$ are used, their efficiency, advantages, and disadvantages have not been evaluated by controlled trials. Preventive measures are expensive in terms of manpower and equipment and can cause patients distress. Thus, instead of all patients receiving prophylactical treatment, only the most vulnerable should be treated as soon as they can be identified.

Over the years the skin clinic at the Municipal Hospital, Copenhagen, has treated about $2 \%$ of all inpatients for pressure sores (5\% of the daily total of inpatients). In 1977 we screened all patients admitted with acute conditions to identify those at risk of developing pressure sores. The group at risk was compared with those not at risk in a fixed sample trial. The effects of two types of mattresses have been described (K E Andersen et al, unpublished observation).

\footnotetext{
Department of Dermatology and Venereology, Municipal Hospital, DK-1399 Copenhagen $K$, Denmark

K E ANDERSEN, CAND MED, senior registrar (present address: Gentofte Hospital, DK-2900 Hellerup, Denmark)

O JENSEN, CAND MED, senior registrar (present address: Skin Clinic, Amagerbrogade 18, DK-2300 Copenhagen S, Denmark)

S A KVORNING, MD, consultant

Danish Institute for Clinical Epidemiology, DK-2100 Copenhagen Ø, Denmark

E BACH, CAND ING, statistician
}

\section{Patients and methods}

Selection of patients-All patients with acute conditions were evaluated on admission. Those already with pressure sores were excluded from the study and treated. A few patients refused to participate and some were included without informed consent because they were unconscious or aphasic. The criteria for inclusion in the at-risk group were based on 15 years' experience of management of pressure sores in the skin clinic.

Risk assessment score-The risk score for each patient was expressed in numerals, 2 for fulfilling the absolute and 1 the relative criteria (table I). Patients with risk scores of two or more were considered to be at risk.

Criteria used to identify patients at risk of developing pressure sores together with classification of skin changes in at-risk group during 10-day observation period

\begin{tabular}{lll}
\hline & Risk criteria & Registered skin changes \\
\hline Absolute (score 2) & Relative (score 1) & $\begin{array}{l}\text { Normal skin } \\
\text { Redness and infiltration } \\
\text { Extravasation } \\
\text { Bullae* }\end{array}$ \\
$\begin{array}{lll}\text { Dehonsciousness } \\
\text { Paralysis }\end{array}$ & $\begin{array}{l}\text { Age ( } \geqslant 70 \text { years) } \\
\text { Restricted mobility } \\
\text { Incontinence }\end{array}$ & $\begin{array}{l}\text { Pronounced emaciation } \\
\text { Redness over bony prominences }\end{array}$ \\
\end{tabular}

*Evidence of pressure sores.

Observation of at-risk group-Since previous experience indicated that most sores occurred soon after admission we examined the patients on alternate days for 10 days. One of us (KEA, OJ, or SAK) assessed the condition of the skin on the shoulders, spine, sacra region, buttocks, hips, and heels. Skin changes were recorded on a form for computer analysis according to the descriptions in the table. Bullae, black necrosis, and skin defects were evidence of pressure sores and were treated; the patient was excluded from further study. A each visit the assessor noted whether the patient was confined to bed, able to sit for two hours a day, or walking. No nursing instructions were given. The initial assessment and frequent visits by the dermatologists made some of the staff more aware of the risk of pressure sores.

Follow-up period-All patients (both at risk and not at risk) were followed up three months after the end of the study. The patients records were reviewed and any pressure sore which developed in the study period recorded. Furthermore we compared the results in the present study with those in a corresponding period in 1976, in which comparable number of patients had been observed.

\section{Results}

Study population-From 17 January to 18 August 1977, 3571 patients were admitted to the acute observation ward. Of these, 55 had pressure sores on admission and 2916 were considered not to be at risk according to the initial assessment. Among the risk. group of 600 patients (corresponding to $16 \%$ of patients admitted), 118 patients were excluded from the study before the first visit by the dermatologist. Of these, 98 were elderly patients, most with fractures of the upper limbs, who scored highly (being over 69 years and having restricted mobility), were correctly included in the study group, and just as correctly discharged for ambulatory treatment with a light bandage. Nineteen patients had been included by mistake, and one was excluded because the kind of mattress he had used had not been recorded.

Risk scores-The risk score was calculated (the lowest being 2 and the highest 7) for the 482 patients in the at-risk group. Theoretically, the maximum score would have been 11 with all criteria fulfilled. During the observation period pressure sores occurred in 35 patients; seven developed bullae, four black necrosis, and 24 skin defects. After 10 days' observation only three more patients developed pressure sores, the last one on day 40 (see figure). In two of these three cases amputa- 
tion of the femur and cardiac arrest explained the late occurrence of the pressure sore.

Non-risk group-Of the 2916 patients with no ulcer or criteria indicating risk of pressure sore on admission, only five $(0.2 \%) \mathrm{de}-$ veloped sores during the study period. Retrospective review of the case records for these patients showed that three of them should have been assessed as at risk and two, who had either had cardiac insufficiency or acute surgery after admission, would have later been assessed as at risk.

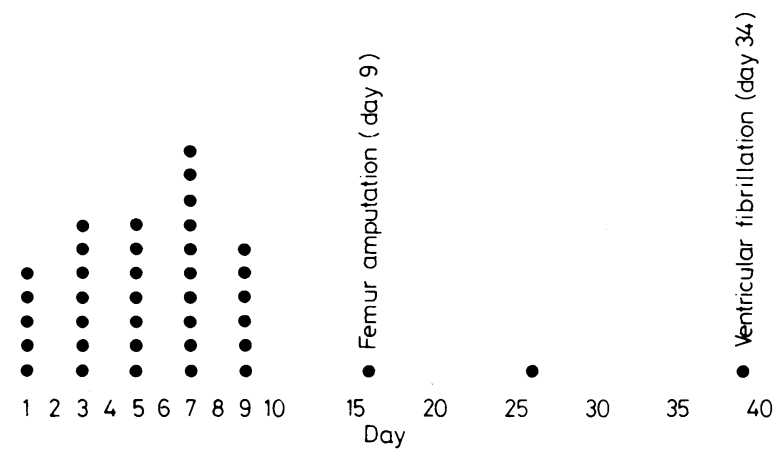

Time (days) at which pressure sores developed in patients at risk.

Incidence-The incidence of pressure sores in the at-risk group rose as the risk score increased. Of 126 patients with local redness on pressure areas on admission, 14 developed sores, all of whom had fulfilled at least three criteria on admission. Persistent redness was not considered a preceding sign when the patient was nursed on a watermattress (one of seven patients). More than half of the pressure sores which developed in patients nursed on ordinary mattresses or airmattresses were preceded by local redness (11/21 and 5/7 patients). The overall incidence of redness over pressure areas was about $20 \%$ for the patients nursed on ordinary and air-mattresses and about $6 \%$ for those on water-mattresses. From January to August in 1976, 104 patients developed pressure sores while in hospital. For the same period in 1977 only 43 patients developed sores; these healed more readily and the patients rarely left hospital with a sore.

\section{Discussion}

Evaluating the risk of pressure sores in all patients admitted with acute conditions by a simple scoring system proved to be efficient, as the incidence of sores in the 600 patients at risk was $5.8 \%$ and only $0.2 \%$ among those not at risk. The Norton risk score is an alternative system which has been successfully used in geriatric institutions. ${ }^{12}$ Grading the four factors, however, requires more knowledge and time than is available in busy emergency wards. Newman and Davis ${ }^{13}$ obtained a high prediction score by using thermography; nevertheless, in $40 \%$ of the geriatric patients the examination could not be carried out.

Since all 35 patients who developed bed sores and fulfilled one absolute criterion had at least one more risk factor the distinction between relative and absolute criteria may not be necessary. Several elderly patients with reduced mobility due to arm fractures were assessed as at risk. This was probably unnecessary as such patients are usually discharged within one or two days. Elderly patients whose mobility is reduced by arthritic pain in hands and elbows are at risk, however, and the criteria, therefore, need to be too wide rather than too narrow. Changes in the risk score system need more experience and data for statistical evaluation.

Persistent local redness as a warning sign of pressure sores is widely accepted, but its predictive value is limited. In this study it was not an indication of risk; pressure sores were preceded by persistent redness in less than half of the patients. Increased mobility reduces the risk of pressure sores but nursing the patient out of bed in a chair does not give complete protection.

Since most pressure sores develop during the first 10 days after admission to hospital, this factor should be considered when inadequate supplies of equipment are distributed.

A comparison of the results in 1976 and 1977 must be judged with caution. The differences between the two study periods were probably due to early detection and the use of immediate prophylactic measures.

We are grateful to the ward staff and hospital administrators for their collaboration and support.

Requests for reprints should be addressed to: Dr S A Kvorning, Department of Dermatology, Municipal Hospital, DK-1399 Copenhagen $\mathrm{K}$, Denmark.

\section{References}

${ }^{1}$ Petersen NC, Bittmann S. The epidemiology of pressure sores. Scand $\mathcal{f}$ Plast Reconstr Surg 1971;6:62-6.

2 Barbanel JC, Jordan MM, Nicol SM, Clark MO. Incidence of pressure sores in the Greater Glasgow Health Board area. Lancet 1977 ;ii:548-50.

${ }^{3}$ Abildgaard U, Daugaard K. Pressure sores. A prevalence investigation. Ugeskr Laeger 1979;141:3147.

4 Coughlin L, Templeton J. Hip fractures in patients with Parkinson's disease. Clin Orthop 1980;148:192-5.

5 Parish LC, Smith G, Collins E. Decubitus ulcers and amyotrophic lateral sclerosis. Lancet 1978 ; : 658 .

${ }^{6}$ Manley M T. Incidence, contributory factors and costs of pressure sores. $S$ Afr Med f 1978;53:217-22.

7 Anonymous. Treating pressure sores. $\mathrm{Br}$ Med $\mathcal{F} 1978 ; \mathrm{i}: 1232$.

8 Bliss MR, McLaren R, Exton-Smith AN. Preventing pressure sores in hospital. Controlled trial of large-celled ripple mattress. Br Med $\mathcal{F} 1967$ i:394-7.

${ }^{9}$ Anonymous. Leaving no ripple. Lancet 1978 ;ii:247-8.

10 Hargest TS. Problems of patients support: the air fluidised bed as a solution. In: Kenedi RM, Cowden JM, Scales JT, eds. Bed sore biomechanics. London and Basingstoke: Macmillan Press 1976:269.

$11 \mathrm{Gibbs}$ JR. Net suspension beds for managing threatened and established pressure sores. I ancet $1977 ; \mathrm{i}: 1974-5$.

12 Norton D, McLaren R, Exton-Smith AN. An investigation of geriatric nursing problems in hospital. Edinburgh: Churchill Livingstone, 1975.

${ }^{13}$ Newman P, Davis NH. Thermography as a predictor of sacral pressure sores. Age Ageing 1981;10:14-8.

(Accepted 5 February 1982)

GENERAL USE OF PHYSIC - I shall desire thee, whoever thou art, that intendest the noble (though too much abused) study of physic, to mind heedfully these following rules; which being well understood, shew thee the Key of Galen and Hippocrates their method of physic: he that useth their method, and is not heedful of these rules, may soon cure one disease, and cause another more desperate. That thou mayest understand what I intend, it is to discover in a general way of the manifest virtues of medicines. I say of the manifest virtues, and qualities, viz. Such as are obvious to the senses, especially to the taste and smell: for it hath been the practice of most Physicians, in these latter ages as well as ours, to say, when they cannot give, nor are minded to study a reason, why an herb, plant, \&c. hath such an operation, or produces such an effect in the body of man: It doth it by an hidden quality, for they not minding the whole creation, as one united body, not knowing what belongs to astral influence, not regarding that excellent harmony the only wise God hath made in a composition of contraries (in the knowledge of which consists the whole ground and foundation of physic) are totally led astray by Tradition.

TEMPERATURE OF MEDICINES-Herbs, plants, and other medicines manifestly operate, either by heat, coldness, dryness, or moisture, for the world being composed of so many qualities, they and only they can be found in the world, and the mixtures of them one with another. But that they may appear as clear as the sun when he is upon the meridian, I shall treat of them severally and in this order 1. Of Medicines temperate, 2. Of Medicines hot, 3. Of Medicines cold, 4. Of Medicines moist, 5. Of Medicines dry. (Nicholas Culpeper (1616-54) The Complete Herbal, 1850.) 